\title{
Alkaline treatment of pine nutshells to improve the treatment of model water from dye methylene blue
}

\author{
Svetlana Sverguzova ${ }^{1 *}$, Ildar Shaikhiev ${ }^{2}$, Julia Voronina $^{1}$ and Olga Doroganova ${ }^{1}$ \\ ${ }^{1}$ Belgorod State Technological University named after V.G. Shukhov, 46 st. Kostyukova, 308012, \\ Russia \\ ${ }^{2}$ Kazan National Research Technological University, 68 st. K. Marx, 420015, Russia
}

\begin{abstract}
In the article presented the data on the possibility of using crushed pine nutshell to extract methylene blue dye from aqueous solutions. In Russia, in Siberia, located up to $80 \%$ of the world's reserves of Siberian cedar pine. Up to 12 million tons of pine nuts can be acquired annually, when processed into kernels or cedar oil, pine nut shell is formed as a waste, representing $51-59 \%$ of the nut weight itself. Despite proposed technological options for usage of pine nutshells, the issue of disposal of this material has not been fully resolved. One of the alternative options for the disposal of pine shells is obtaining sorption material for the extraction of pollutants from aqueous media. To improve the cleaning efficiency, the pine shell was treated with $10 \% \mathrm{NaOH}$ solution. It was found that processing pine nutshells with $10 \% \mathrm{NaOH}$ solution for 5 minutes at a temperature of $25{ }^{\circ} \mathrm{C}$ gives an improvement in cleaning efficiency of $96 \%$, and an increase in the temperature of $\mathrm{NaOH}$ solution up to $97 \%$. The recommended particle size of the pine nuts shell is less than $2 \mathrm{~mm}$.
\end{abstract}

\section{Introduction}

The most environmentally sound technologies with high efficiency include methods of sorption wastewater treatment. The main criterion for choosing a sorption material for wastewater treatment is its sorption properties, porous structure and profitability.

The most popular in the wastewater treatment from heavy metal ions are carbon sorbents, silica, peat, ash and other industrial wastes [1-19].

Different brands of activated carbons during sorption of heavy metal ions have a greater or lesser absorption capacity. The main factor, that determines the cleaning efficiency of the sorption method, is the $\mathrm{pH}$ value. At $\mathrm{pH}=4$, sorption maximum is reached, i.e. the process goes to the formation of hydrolysis products. Granulated activated carbon, saturated with nitrohumic acid, has a high absorption capacity towards to heavy metal ions. For the 
treatment of wastewater from heavy metal ions at initial concentrations up to $10 \mathrm{mg} / 1$, xanthates (dithiocarbamates) starch is promising sorption material. [8, 20]. ${ }^{*}$

Coals, acquired by burning solid plant waste from the food industry and hydrolysis lignin waste, have the ability to sorb heavy metal ions from solutions [21-26]. Sorption technologies are economically profitable on the condition for reuse of sorption material.

After regeneration of the sorbents, highly toxic and highly concentrated extracts are formed, which needs to be additionally neutralized and due to that, the issues of the disposal of spent sorption material. Therefore, cleaning methods based on ion exchange using natural and synthetic materials that allow not only to extract recoverable metals from wastewater, but also to reuse wastewater in closed water supply systems are receiving more and more attention $[5,7,10,13]$.

\section{Methods}

The authors of the article propose to use pine shells for the extraction of dye methylene blue (MB) from aqueous media (PN).

In Russia, in Siberia, located up to $80 \%$ of the world's reserves of Siberian cedar pine. Up to 12 million tons of pine nuts can be acquired annually, when processed into kernels or cedar oil, pine nut shell is formed as a waste, representing $51-59 \%$ of the nut weight itself. [23]. As a result, the production of PN waste, according to estimates, is on average about 58 million tons per year. The resulting biomass from the shell needs to be disposed, to obtain useful and valuable products, since PN - is a unique source of carbohydrate-mineral complex and various organic substances. The chemical composition of pine nutshells includes: fiber, fats and resins, proteins, essential oils, vitamins, coloring and tannins. Each year, experts offer new technological options for creating materials from any part of cedar pine. One of the alternative options for the disposal of pine shells is obtaining sorption material for the extraction of pollutants from industrial wastewater and drinking water. As well as in the production of vanillin and as colmatants and fillers for drilling fluids during the construction of wells.

It should be noted, that the issues of large-tonnage PN utilization haven't been resolved, and the accumulation of large quantities of $\mathrm{PN}$, which is little susceptible to degradation processes under environmental conditions, can lead to the formation of dumps and the rejection of useful materials to agricultural land.

PN contains a significant amount of lignin (an aromatic residue that is not hydrolyzable in $72 \%$ sulfuric acid), which, in the content of active functional groups, fully corresponds to native (natural) lignin. The required fraction of the material was selected by sifting. Sifting was performed in a "dry" way (sifted through a set of standard sieves manually) using a standard set of sieves: $0.5-1 \mathrm{~mm} ; 1-2 \mathrm{~mm} ; 2-5 \mathrm{~mm}$; $5-10 \mathrm{~mm}$.

The poured density of PN was determined by calculating the ratio of the mass of the material to the occupied volume; the $\mathrm{pH}$ of the aqueous extract was determined using a $\mathrm{pH}$ meter brand I-500. True density was determined by the pycnometric method. Losses during calcination were determined by calculating the ratio of the difference in the weight of the crucible with the sample before and after calcination to the mass of the initial sample.

The concentration of MB in the solutions was determined by the photocolorimetric method using the construction of a calibration graph. The cleaning efficiency was judged

\footnotetext{
* Corresponding author: sv.anastasiaa@mail.ru
} 
by the change in the optical density of the MB solution after the contact with PN. For this purpose, weighed material was used with a mass in the range $\mathrm{m}=0.25-1.0 \mathrm{~g}$, particle size $\mathrm{d}$ $=1.0-2.0 \mathrm{~mm}$, which were added to flasks with a methylene blue solution $\mathrm{V}=100 \mathrm{ml}$. On the LS-110 mixing device, the contents of the flask were shaken for 20 minutes, then the solutions were filtered through the paper filter «Blue Ribbon» TU6-09-1678-95, and measured optical density of the filtrate on a photocolorimeter KFK-2-UHL4,2 GOST 15150-69 (wavelength $\lambda=670 \mathrm{~nm}$, sensitivity 3 , filter red).

The cleaning efficiency (E, \%) was calculated by the formula:

$$
\ni=\left(\mathrm{C}_{1}-\mathrm{C}_{2}\right) / \mathrm{C}_{1} \cdot 100
$$

where $C_{1}$ - initial dye concentration in wastewater, $\mathrm{mg} / \mathrm{l} ; C_{2}$ - residual dye concentration in purified water, $\mathrm{mg} / \mathrm{l}$.

\section{Results and Discussion}

Due to the fact that PN contains a certain amount of cedar oil, the surface of the material has hydrophobic properties. This prevents the penetration of the aqueous solution into the PN particles and makes the MB extraction process ineffective. To degrease the surface of the PN particles and to increase their hydrophilicity, PN was treated with a $10 \% \mathrm{NaOH}$ solution for a specified time. After treatment, the material was washed until neutral, dried and used to clean model solutions.

Next, the concentrations of the MB solution before and after purification were compared. The research results are presented in Fig.1

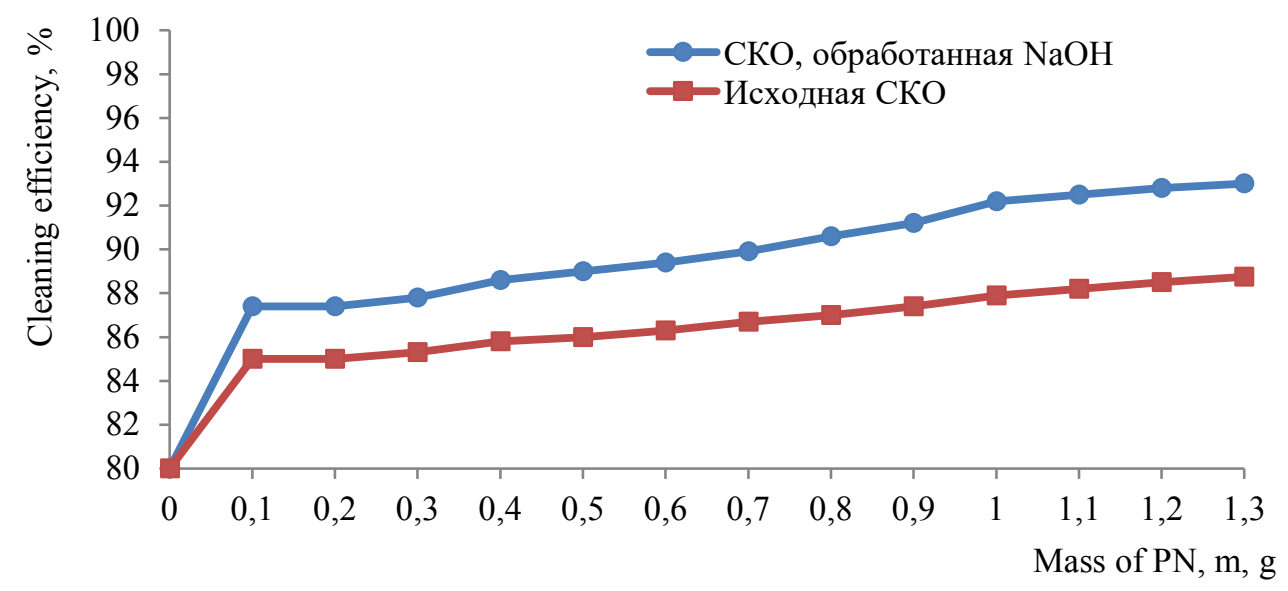

Fig. 1. The dependence of the cleaning efficiency (E, \%) from the mass of the initial PN and PN treated with $\mathrm{NaOH}$

A comparison of the graphs (Fig. 1) shows an increase in the solution cleaning efficiency from $85 \%$ to $88.75 \%$ in the selected mass interval of the added initial PN. Treatment of the same mass of PN with the $10 \% \mathrm{NaOH}$ solution for 5 minutes at a temperature of $250 \mathrm{C}$ gives an improvement in cleaning efficiency from $87.4 \%$ to $93 \%$.

The graph of the dependence of the cleaning efficiency from the contact time PN with the model solution MB (Fig. 2) shows that the rational contact time is 20 minutes, the cleaning 
efficiency $\mathrm{E}=88 \%$, a further increase in the contact time up to 50 minutes leads to an improvement in the cleaning efficiency up to $\mathrm{E}=90 \%$.

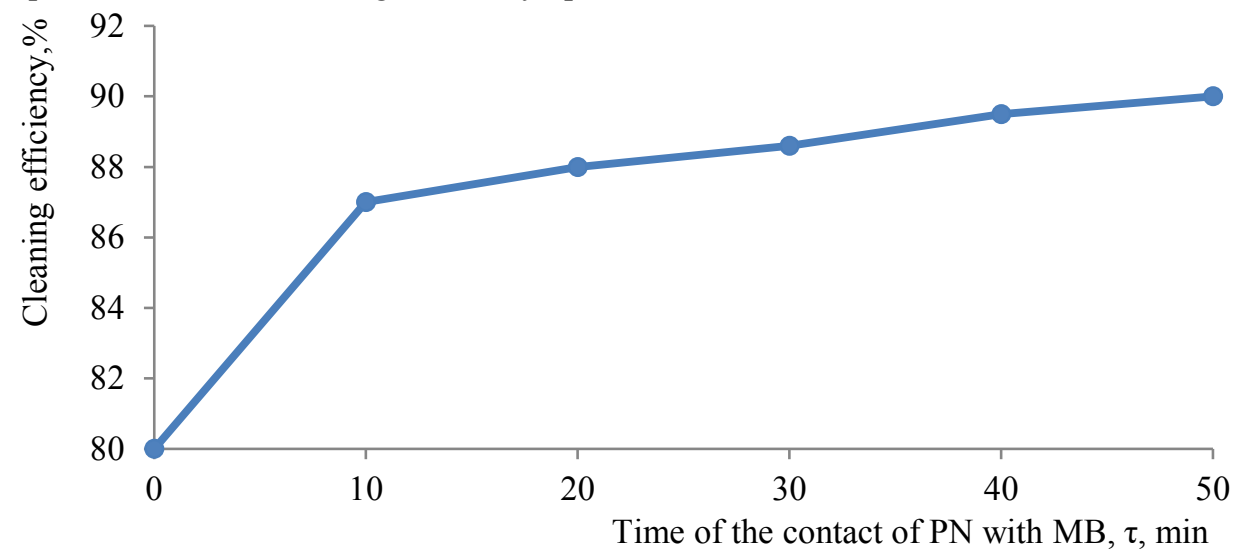

Fig 2. The dependence of the cleaning efficiency (E, \%) from the contact time of the initial PN with the model solution MB (Cinitial=20 mg/dm3, V=100 cm3, $\mathrm{m}=1 \mathrm{~g}, \mathrm{t}=20 \pm 10 \mathrm{C}$, particle size 1,0-2,0mm)

The graph of the dependence of the cleaning efficiency from the temperature of the model solution MB (Fig. 3) shows that the highest cleaning efficiency is observed at the temperature $\mathrm{t}=20 \pm 10^{\circ} \mathrm{C}(\mathrm{E}=88 \%)$, a further increase in temperature is impractical.

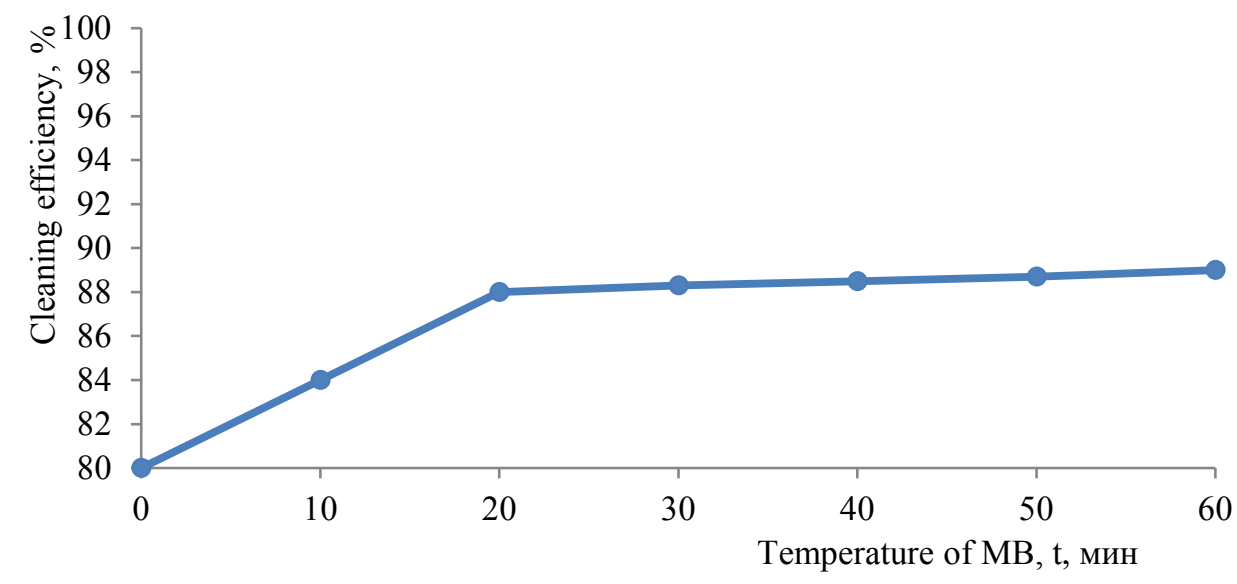

Fig. 3. The dependence of the cleaning efficiency (E, \%) from the temperature of the model solution MB (Cinitial=20 mg/dm3, V=100 cm3, m=1g, $\tau=20 \mathrm{~min}$, particle size 1,0-2,0mm)

The graph of the dependence of the cleaning efficiency from the particle size PN (Fig. 4) shows that the highest cleaning efficiency is observed for fractions with particle sizes of $0.5-1.0 \mathrm{~mm}$ and $1.0-2.0 \mathrm{~mm}$. 


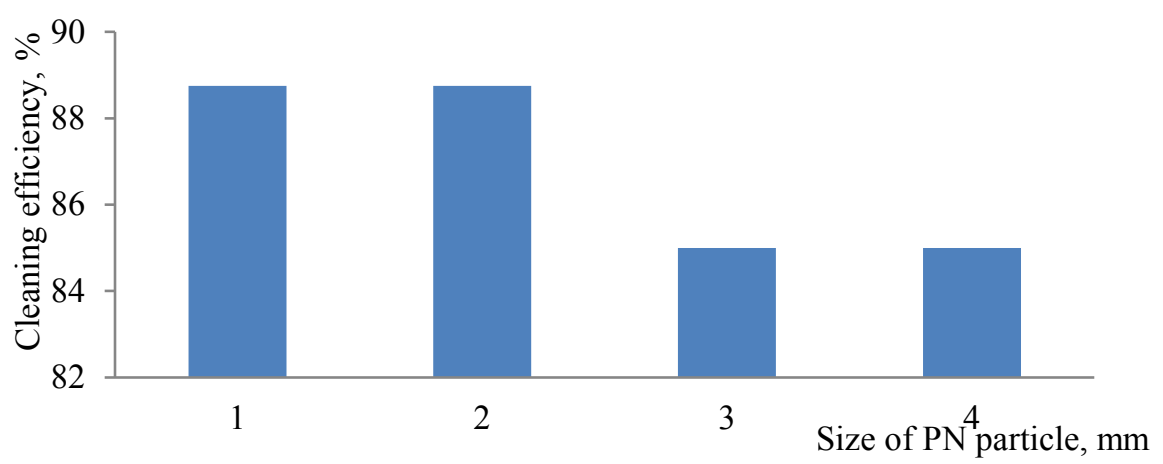

Fig. 4. The dependence of the cleaning efficiency from the particle size of the PN (Cinitial $=20$ $\mathrm{mg} / \mathrm{dm} 3, \mathrm{~V}=100 \mathrm{dm} 3, \mathrm{~m}=1 \mathrm{~g}, \tau=20 \mathrm{~min} ., \mathrm{t}=25 \pm 10 \mathrm{C})$; particle size $1(0,5-1,0 \mathrm{~mm}) ; 2(1,0-2,0 \mathrm{~mm}) ; 3(2,0-$ $5,0 \mathrm{~mm}) ; 4(5,0-10,0 \mathrm{~mm})$

An increase in the duration and increase in the temperature of alkaline treatment of RMS leads to an improvement in the cleaning efficiency (Fig. 5).

a

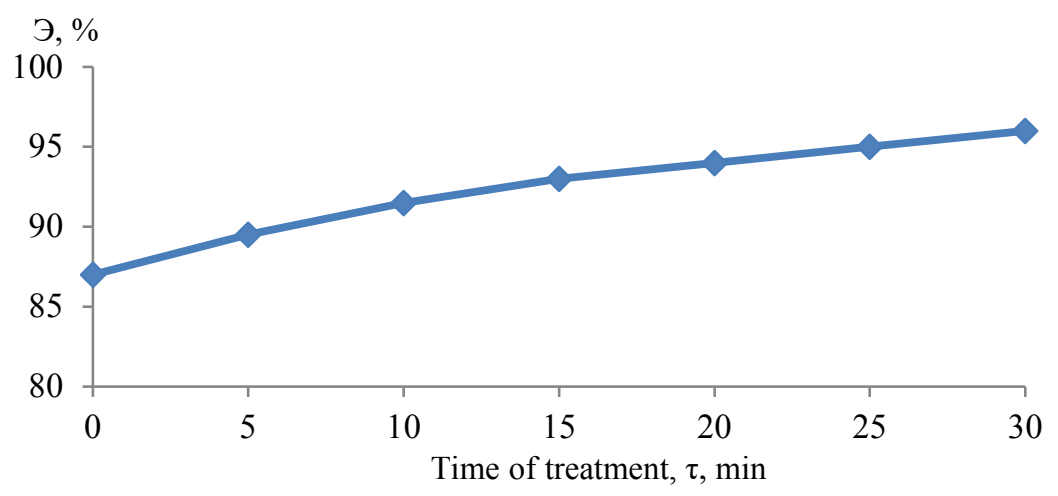

6

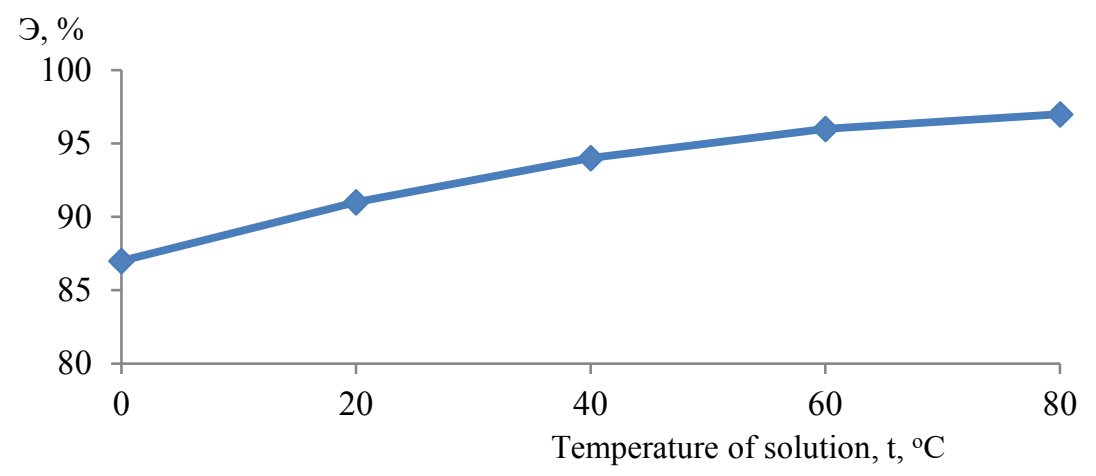

Fig. 5. The dependence of the solution cleaning efficiency from MB from the processing time (a) and the temperature of the alkaline solution (b) 
It can be seen on presented results, that an increase in the processing time of the material from 5 to 30 minutes leads to an increase in the cleaning efficiency from 87 to $96 \%$, and an increase in the temperature of the alkaline solution improves the cleaning efficiency to $97 \%$

\section{Summary}

Thus, in the article was studied the possibility of improving the efficiency of cleaning solutions from methylene blue with the pine nutshells treated with a $10 \%$ solution of $\mathrm{NaOH}$. It was determined, that maximum efficiency of a methylene blue solution with an initial concentration of $20 \mathrm{mg} / \mathrm{dm}^{3}$ when treated with an alkali solution for 30 minutes is $96 \%$, and an increase in the temperature of an alkaline solution to $80^{\circ} \mathrm{C}$ allows to achieve a cleaning efficiency of $97 \%$. The recommended particle size of pine nutshells is less than $2 \mathrm{~mm}$.

\section{Acknowledgement}

The work is realized in the framework of the Program of flagship university development on the base of the Belgorod State Technological University named after V.G. Shukhov, using equipment of High Technology Center at BSTU named after V.G. Shukhov.

\section{References}

1. S.V. Sverguzova, G.I. Tarasova, I.V. Starostina, A.A. Vnukov, M.Y. Fedorina, Composite pigment-filler on the basis of sludge of heat power plant and tails of engichment of ferruterous quartzites (SCOPUS), Research Journal of Applied Sciences v.10(12), pp. 827-831 (2015)

2. S.V. Sverguzova, I.V. Starostina, G.I. Tarasova, E.V. Fomina, Using Ferruginous Quartzite Tailings In Dry Building Mixes, International Journal of Applied Engineering Research. v. 10 (24), pp.45082-45090 (2015)

3. I.V. Starostina, S.V. Sverguzova, I.V. Ovcharova, P.V. Besedin, E.A. Pendurin, E.M. Kuzina, Recycling of microbiological industry waster with the obtaining of foaming agents for building industry, International Journal of Applied Engineering Research, v. 10(21), pp. $42701-42706$ (2015)

4. D. Bae, K. Seff, Microporous and Mesoporous Materials, 40(I)(1-3), 219-232 (2000).

5. K. Dohpalir, Wodzie das Wodatechnikasanitarna, 10, 342-346 (1971).

6. A. Netzer, D.E. Hughes, Water Res, v. 18(8), 927-933 (1984).

7. M. Sprynskyy, Journal of Hazardous Materials, v. 161 (I) (2-3) 1377-1383 (2009).

8. M. Al-Anber, Z. A. Al-Anber, Desalination, 225(I)(1-3) 70-81 (2008).

9. D. Couillard, Water Research, 28(6), 1261-1274 (1994).

10. N. Rajic, D. Stojakovic, M. Jovanovic, N. Zabukovec Logar, M. Mazaj, V. Kaucic, Applied Surface Science, 257(I)(5), 1524-1532 (2010)

11. S. Ahmed, S. Chughtai, M.A. Keane, Separation and Purification Technology, 13(I)(1), 57-64 (1998) 
12. M. Vukčević, B. Pejić, A. Kalijadis, I. PajićLijaković, M. Kostić, Z. Laušević, M. Laušević, Chemical Engineering Journal, 235(1), 284-292 (2014)

13. D. Rodrigues, T.A.P. Rocha-Santos, A.C. Freitas, A.M.P. Gomes, A.C. Duarte, Science of The Total Environment, 461-462 (9), 126-138 (2013)

14. B. Nowak, P. Aschenbrenner, F. Winter, Fuel Processing Technology, 105(1), 195-201 (2013)

15. S.V. Sverguzova, M.Zh. Gomez, A.V. Shamshurov, V.V. Tarasov, V.D. Mukhacheva, Bulletin of BSTU named after V.G. Shukhov, 4, 164-167 (2014)

16. I.G. Shaikhiev, S.V. Sverguzova, A.I. Yusupova, R.Z. Galimova, Bulletin of the University of Technology, 21(6), 77-82 (2018)

17. S.V. Sverguzova, I.G. Shaikhiev, A.S. Grechina, K.I. Shaykhieva, Economics of construction and environmental management, 2 (67), 51-60 (2018)

18. I.G. Shaikhiev, S.V. Sverguzova, J.A. Sapronova. R.R. Valiev, Bulletin of the Kamchatka State Technical University, 45, 6-11 (2018)

19. S.V. Sverguzova, J.A. Sapronova, Ecology and industry of Russia, 20(7), 26-29 (2016)

20. R.E. Environ, Program, 2(4), 269-272 (1983).

21. A.K. Zapolsky, V.V. Samples, Integrated wastewater treatment of the galvanic production, (K .: Tekhnika, 1989)

22. S.V. Sverguzova, S.V. Stepanova, I.G. Shaikhiev, Purification of model effluents containing heavy metal ions, wheat husk. Bulletin of BSTU named after V.G. Shukhov, v. 6, pp.187-191 (2014)

23. S.V. Sverguzova, J.A. Sapronova, I.G. Shaikhiev, D.V. Sapronov, The use of corn processing waste for the purification of aqueous media from the dye "methylene blue", Bulletin of Kazan Technological University, v. 17(5), pp. 173-175(2014)

24. S.V. Sverguzova, I.G. Shaikhiev, A.S. Grechina, K.I. Shaykhieva, The use of waste from the processing of oat biomass as sorption materials for the removal of pollutants from aqueous media, Economics of construction and environmental management, 2(67), pp. 51-60 (2018)

25. S.V. Sverguzova, A.I. Yusupova, R.Z. Galimova, I.G. Shaikhiev, Sorption purification of model solutions of iron (III) ions by sawdust of bark and foliage of oak oak, Bulletin of the Technological University (Kazan), 21(6), pp. 35-41 (2018)

26. S.V. Sverguzova, J.A. Sapronova, A.V. Svyatchenko, T. Otiti, Adsorption of spindle oil by native and thermally modified leaf litter of chestnuts, Construction Materials and Products, v. 1(1), pp. 4-11 (2018) 